Utah State University

DigitalCommons@USU

\title{
The Effects of Gender Communication Patterns on Opposite Gender Attraction
}

Robert R. Wright

Utah State University

Follow this and additional works at: https://digitalcommons.usu.edu/honors

Part of the Psychology Commons

\section{Recommended Citation}

Wright, Robert R., "The Effects of Gender Communication Patterns on Opposite Gender Attraction" (2006). Undergraduate Honors Capstone Projects. 701.

https://digitalcommons.usu.edu/honors/701

This Thesis is brought to you for free and open access by the Honors Program at DigitalCommons@USU. It has been accepted for inclusion in Undergraduate Honors Capstone Projects by an authorized administrator of DigitalCommons@USU. For more information, please contact digitalcommons@usu.edu.

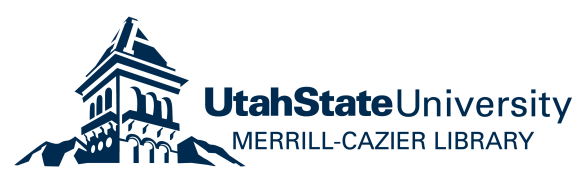




\title{
THE EFFECTS OF GENDER COMMUNICATION PATTERNS ON OPPOSITE GENDER ATTRACTION
}

\author{
by
}

Robert R. Wright

Thesis submitted in partial fulfillment

of the requirements for the degree

of

DEPARTMENT HONORS

in

Psychology

Approved:

Thesis/Project Advisor

Department Honors Advisor

$\underline{\text { Scott C. Bates }}$

$\underline{\text { Scott C. Bates }}$

Director of Honors Program

Christie Fox

UTAH STATE UNIVERSITY

Logan, UT 
ATTRACTION AND COMMUNICATION PATTERNS

The Effects of Gender Communication Patterns on Opposite Gender Attraction

Robert Wright

Scott C. Bates, Ph.D

Tamara J. Ferguson, Ph.D.

Utah State University 


\section{Abstract}

The Effects of Gender Communication Patterns on Opposite Gender Attraction Wright RR, Bates SC, Ferguson TJ

Utah State University, Logan, UT

Female patterns of speech communication including expression of empathy, sharing similar experiences, and asking further questions were compared to typical male patterns of communication in gender attraction. Self-report methods were employed in the administration of the Attractive Communication Styles Survey and the Conversation Survey Questionnaire. With a convenience sample of 164, both survey instruments assessed for differences of attraction between the two conversation styles. Analyses revealed both males and females valuing the typical female pattern of communication, but differed in the intensity of support with females strongly favoring and males slightly favoring the female pattern $(6.350(72)=x, p<.01 ; 13.811(90)=x, p<.01)$. However, both males and females exhibited statistical differences in all their responses for the female pattern, except when asked which they were attracted to the most romantically $(p=.064)$. Implications for further research on the actual dyadic interaction effects on attraction are supported. 


\section{Introduction}

Attraction has been an area of interest for psychologists, doctors, and social workers even before ways to measure attraction had been developed. Those factors that influence attraction and determine attraction between two individuals and, at the same time, denote a lack of attraction between two other individuals have often become the subjects of study. The area of research on attraction of the genders is broad and extensive (Buss, 1989; Cramer \& Schaeffer, 1996; Kalof, 1999; Regan \& Joshi, 2003; Rowatt, Cunningham \& Druen, 1999; Sprecher \& Regan, 2002). Personality characteristics, evolutionary forces, physical appearance, and comparisons of different types of attraction have been studied in order to locate those issues, which determine attraction to one individual over another. Researchers largely agree that personality characteristics play a role in mate selection and attraction, but the extent to which these characteristics determine attraction is unknown (Cramer \& Schaeffer, 1996; Regan \& Joshi, 2003; Sprecher \& Regan, 2002). Buss (1989) also identified evolutionary forces as possible determinants of attraction and those results parallel other findings on physical appearances (Buss, 1989; Rowatt et al., 1999) Attraction has an interactive component creating a construct which depends on all of these factors that have been identified as influencing the degree of attraction individuals may experience to others of the opposite gender.

\section{Intrinsic Values and Attraction}

Various personality characteristics and intrinsic values (e.g. social skills, personality) do have an impact on attraction between the genders. Although there are many differences in attraction factors between the genders, personality characteristics like intelligence, humor, and intellect are highly valued by both (Regan \& Joshi, 2003). However, this was only true when the participants considered their partner in a long-term romantic relationship. Other characteristics such 
as warmth and kindness, expressiveness and openness, and a sense of humor also play a critical role in attraction (Sprecher \& Regan, 2002). Especially in romantic relationships, social competence and other socially interactive components of the personality are consistently rated as of more importance in determining attraction than other factors (Regan \& Joshi, 2003; Sprecher \& Regan, 2002). A possible explanation of this may be that it is socially acceptable to have many friends, but having more than one romantic partner at a time is not. Only having one partner implies a lack of variability in social situations and having someone who is competent in social occasions may be seen as beneficial. Rating intrinsic values as more important than other attraction factors may be a direct result from being limited to one partner (Sprecher \& Regan, 2002).

It has been determined that personality is a substantial factor in gender attraction. However, different personality characteristics are valued above other characteristics in regards to conditions that individuals are placed in. Regan \& Joshi (2003) found that when adolescents were asked what they valued most in a mate, long-term relationships and short-term relationships influenced the types of responses the participants gave. Those who were asked about long-term relationships valued the potential partner's social interaction ability as being more important than physical characteristics. Short-term relationships had a higher value for physical characteristics over personality. A possible explanation for this is that short-term may imply that extensive social interaction will not occur and will be unnecessary to fulfill the expectations of a successful relationship. As a result, intrinsic values will not be valued and desired as much as other factors, such as physical appearance.

The type of relationship is another variable that influences attraction and what is most important in attraction. Across all types of relationships, friendship or romantic, those qualities that imply social competence and social support are rated a higher importance in a partner than the 
physical qualities of an individual (Sprecher \& Regan, 2002). This may be a consequence of many people choosing romantic partners from their existing groups of friends (Sprecher \& Regan, 2002). If so, attraction between the genders commences before intimate relationships even begin and starts once the individual has determined that the person of the opposite sex fits the criteria of being a friend. More evidence of this is exhibited in the tendency for people to rate the same intrinsic values they desire in friends as of higher importance in their romantic relationship partners.

Although no gender differences exist between preferences of the various values of personality (Regan \& Joshi, 2003), gender differences do surface in relation to ratings of physical attractiveness and how important it is (Cramer \& Schaeffer, 1996; Sprecher \& Regan, 2002). Specifically, men do rate the attractiveness of women in regards to physical appearance as more important than women do with men (Cramer \& Schaeffer, 1996). The ideal mate for a male has been identified as one who had "high reproductive value" - young and fertile, active and healthy, and attractive and sexually responsive (Cramer $\&$ Schaeffer). This may account for the emphasis that men place on the physical attractiveness of women. In fact, men are more likely to connect physically attractive women with positive and successful relationships (Kalof, 1999). Women, however, rated physical attractiveness important only after satisfying the desire for education and good earning capacity in their prospective partners (Cramer \& Schaeffer, 1996). Other studies have found other similar results that support these conclusions, but all of these results can only be as accurate as self-report studies can be (Buss, 1989; Kalof, 1999). More interactive and observationbased studies may be appropriate before these results can be generalized to the population.

The length of the prospective relationship is another critical factor when considering attraction. When long-term romantic relationships are compared with casual short-term romantic relationships, Regan \& Joshi (2003) found that adolescents had a much greater preference for an 
attractive external, physical appearance. Along with the physical appearance, sexual passion was also determined to be of more importance for a short-term relationship. Interestingly, no gender differences were found in this study (Regan \& Joshi, 2003). The typical stereotype of a man suggests that he would be more interested in the physical qualities of a partner than a woman would be. Although a great deal of research does support this (Buss, 1989; Cramer \& Schaeffer, 1996; Kalof, 1999), this study refutes this stereotype of men and physical attraction (Regan \& Joshi, 2003).

Men and women do have other similarities in their desires to obtain physically attractive opposite-gender partners. Rowatt et al. (1999) tested the willingness of men and women to lie to prospective dates about their own appearance and personality. Amazingly, men and women demonstrated a substantial degree of similarity in being willing to lie about themselves in order to get a physically attractive date. By exaggerating possible similarities between the two parties, men and women were more willing to lie about their physical appearance to their attractive prospects rather than lie about their own personalities. This holds true with the theory that attractive people will search out attractive partners. By lying to perceived attractive date prospects, the participants were hoping for a better chance of success by appearing more physically attractive.

\section{Evolutionary Perspective of Attraction}

One of the largest gender attraction studies ever conducted concludes that evolution is the driving force behind attraction of the genders regardless of other possible confounding variables such as culture. Buss (1989), argues that men and women are inherently different in their mating strategies and mate preferences due to the evolutionary processes of survival of the fittest and natural selection. Those men who do not find a suitable mate to pass on his genes are not successful in society. Likewise, those women who do not find a suitable mate for protection and care of the 
young offspring are not successful in their roles of maintaining their species in nature. The evolutionary approach to attraction simply states that: men are more attracted to women capable of childbearing and women are attracted to those men who can offer protection and stability.

In transition from early history to now, the basic instincts of survival and procreation are known by different labels. Men value youthful, fertile, healthy, and physically attractive women because they have higher potential for successful reproduction (Buss, 1989; Cramer \& Schaeffer, 1996). Women, on the other hand, value high-resource potential in men, which implies a better protective environment. Those men who are seen as ambitious, socially competent, motivated, intelligent, honest, college educated, and who have a high earning capacity are much more attractive to women (Buss, 1989; Cramer \& Schaeffer, 1996).

According to the evolutionary theory of attraction, parental investment plays a key role. Women have a much longer time of parental investment with their offspring than men do. As a consequence, women should look to men that will be dependable, supportive, protective, have an ability to provide for the offspring, and care for the woman (Buss, 1989). Those men that are older and have more experience are seen as more attractive than those who have less experience or who are younger (Buss, 1989). However, women do not value physical appearance that would be associated with higher fertility capability in men to the extent that men value it in women. That is due to the fact that men's fertility is not as distinguishable from physical characteristics as are the future fertility of women by their physical appearances (Buss, 1989).

Although future fertility, physical appearance, and providing capability are ranked highly by this evolutionary perspective, basic social skills, intrinsic values, and personality factors are still valued more in romantic relationships (Regan \& Joshi, 2003; Sprecher \& Regan, 2002). This finding suggests that attraction is based on those social interactive elements of personality in a 
possible relationship. Communication is the method of interaction between individuals and has a substantial effect on attraction between the genders. In fact, communication is very often a way to separate the genders even further into their own distinct "cultures" (Edwards \& Hamilton, 2004; MacGeorge et al., 2004; Tannen, 1990).

\section{Communication Patterns of the Genders}

According to Tannen (1990), women and men are vastly different in their approaches to communicating with one another. Women generally focus on intimacy and men have a tendency to value independence much more than women do in their communications. This causes friction between the sexes as both attempt to understand one another's communication patterns through their own communication contexts (Tannen, 1990). Misunderstandings, frustration, and perplexity are all by-products of such a communication design (Edwards \& Hamilton, 2004). Furthermore, men are more likely to view themselves in a hierarchal society where they are either one-up or onedown in comparison to the rest of society (Tannen, 1990). Of course, that would explain the general stereotype of men being more aggressive and competitive than women are. On the contrary, women see the community in a more communal, intimate way. Women want intimacy, trust, and emotional support from those whom they come in contact with, rather than competition (Edwards \& Hamilton, 2004; MacGeorge et al., 2004; Tannen, 1990).

Boys, at an early age, are taught that language is a vehicle for accomplishing instrumental tasks, conveying important information, and maintaining status and autonomy (MacGeorge et al., 2004). As a result, boys value close relationships for their instrumental features and functions. Girls, on the other hand, are socialized to believe that close relationships serve emotional and expressive functions. Language and talk are the media for girls to express themselves, communicate feelings, and to develop intimacy and trust with others (MacGeorge et al., 2004). The 
gender-dependent beliefs regarding communication are quite different, but do lead to the same intended outcomes of successful communication of thought and ideas, implying that one communication pattern is not superior to the other (MacGeorge et al., 2004).

Although men see their communicative efforts with women as nonassuming and respectful, women interpret their communication techniques as belittling, dismissive, and as "talk" devoid of empathy (MacGeorge et al., 2004; Tannen, 1990). This influences another difference in communication under the "different cultures" theory. Men are generally more prone to be problem solvers and see communication as a means to solve problems. As women express their problems through communication to men, men take their usual role and attempt to aid women with their problems (Tannen, 1990). In contrast, women, who value intimacy and empathy, focus on listening and understanding as men speak to them (Tannen, 1990). Therefore, women tell men their problems and receive problem-solving solutions. Likewise, as men express themselves to women, they receive understanding and empathy instead of the problem-solving solutions they may have desired to begin with. These situations and communication tendencies all serve to add to the confusion and misunderstandings between the genders.

However, other supporters of this "different cultures" theory reveal positive benefits of different communication styles. One study that attempted to prove Tannen's (1990) theories discovered that when both a supportive, nurturing orientation and an assertive, competitive orientation are present in a relationship they serve to eliminate possible cross-sex miscommunications (Edwards \& Hamilton, 2004). Several different scenarios were given to the participants where they rated cooperativeness of the individuals involved, dominance and nurturance displayed, and cross-sex miscommunication. Edwards \& Hamilton (2004) suggests that not only are the two different styles fully functional in purpose, but that there is a protective quality 
in both types of these communications. When communication is seen as beneficial to both parties and cooperation the goal, miscommunication between the genders was significantly decreased. Likewise, when both stereotypical communication patterns of the sexes are present, regardless of the gender that maintains those patterns, misunderstandings and miscommunications are at a minimum (Edwards \& Hamilton, 2004).

Men are also more prone not to express themselves in emotional ways that deal with pleasantness, disgust, fear, and anger (Wagner, Buck \& Winterbotham, 1993). Socialization may be responsible for their learned responses of suppression of these emotions (Wagner, 1993). Although there is a general lack of expression of emotion by men, Wagner et al. (1993) found that regardless of the gender of those who send emotional messages, men do experience emotions in a similar way to women. Therefore, gender differences are due to expression of emotion and not the actual experience of the emotion. Women showed a much greater advantage of communicating, interpreting, and displaying emotions over men as both genders were entreated to view a slide show regarding emotional expression. However, women do have a tendency to exaggerate their displays of emotional communication. This may be in response to a need of women for further social support and clarity in their communication (Wagner et al., 1993). However, all gender differences in expressiveness seem to be dependent on the particular emotional stimulus at hand, the nature of the activity in which the sender is engaged, and on the interpersonal situation (Wagner et al., 1993).

\section{Gender Communication and Attraction}

In an attempt to find the most socially attractive model of communication, Feldstein et al. (2001) had both genders rate each other on their speed of speech in relation to social attractiveness. A Likert-type scale was used where dependent variables of perceived competence and social attractiveness were measured as the perceived rate of speech altered between the participants. The 
perceived rate of speech varied on a spectrum of speed from fast to slow speaking. Women were observed to rate all the speakers as more competent than did the male listeners and all the listeners considered the male speakers to be more socially attractive than the female speakers (Feldstein et al., 2001). The different strategies of communicative presentation of men and women may have an influence on this finding. The general strategy of men to use a "status assertive mode" by using language as a vehicle to establish their status in situations and for women to use communication to be more affiliative and interpersonally positive with others may have influenced the results of the study (Feldstein et al., 2001). Most importantly, however, Feldstein et al. (2001) supports the conclusion that people tend to like others with similar attitudes, interests, and personality characteristics, or at least those whom they perceive to be similar to themselves. Those speakers whose speech rates were the most similar to the listener's were rated as most socially attractive (Fedlstein et al., 2001). This lends support to the idea that mimicking another person's speech patterns are, in fact, attractive to the other person.

Verbal behavior and verbal communication are not the only media of communication that may impact gender attraction. Gaze behavior also has an impact on attraction in negative and positive ways. Gaze aversion elicits a negative response from the observer and denotes a negative communicative intent (Burgoon, Coker \& Coker, 1986). Specifically, gaze aversion contributes to the observers' feelings of nonimmediacy, nonaffection, nonreceptivity, lack of trust, dissimilarity, and superficiality about the other person (Burgoon et al., 1986). However, constant gaze is not necessarily always seen as a positive form of communication. Since gaze was the only manipulated behavioral variable (high, normal, and low) in this study, gaze levels correlated with the emotional reaction of the participants. Burgoon, et al. (1986), found that nearly constant levels of gaze during interaction are not perceived as necessarily more favorable than normal levels of gaze. Gaze is a 
widel|y used way of communicating and decoding others' emotional expressions, but the specificity and direction of the emotion eliciting the gaze behavior may be frequently misunderstood.

Burgoon et al. (1986) showed gender differences as major factors in determining interpretations of the confederates' varying gaze levels. Men were consistently given more favorable interpretations for their gaze behavior and rated more credible, attractive, and hirable than women were. Those individual men seen as rewarding to speak with (for more specific information consult Burgoon, et al. 1986) who used high gaze were seen as dominant and those rewarding females, which were in the high gaze condition were perceived as more submissive. This study lends more support that submissive women and dominant men are rated as more attractive and that gaze interpretation can be very subjective in both genders (Burgoon et al., 1986).

Other nonverbal behaviors that may have effects on attraction include: facial expressions, voice tones, and body expressiveness. Raines, Hechtman, \& Rosenthal (1990) used four different conditions: face only, voice only, body only, and a combination of all three channels to analyze their effect on attraction. In the face only condition, facial features did have a substantial impact on how both genders rated the others' attractiveness (Raines et al., 1990). Voice tones do have an effect, but observations indicated that much of attraction is based on visual stimuli rather than audible (Raines et al., 1990). Whereas facial expressions had an influential impact on perceived attraction in both genders, only women show an effect according to body expressions (Raines et al., 1990). Another interesting finding of this study parallels the previous study: those women rated as more submissive and those men rated as more dominant were significantly rated as more attractive to the other gender respectively. This may influence others' perceptions of those who are seen as submissive and dominant and lead to an overall better treatment of those they rate higher in 
attraction than those who are not associated with these characteristics in communication (Burgoon et al., 1986; Raines et al., 1990).

Although typically categorized as a woman-related communication pattern, Montgomery (1986) used open communication, a process by which personal information is inferred from verbal and nonverbal behavior, as an independent variable in relation to attraction. The results of this study support the general conclusion that open communication can accurately predict interpersonal attraction. Participants in this study were asked to have a discussion with each other and after completing the discussion, a measure for peer attraction and open communication were administered. When determining attraction, the participants relied upon stylistic communication components rather than content components in the speakers' speech (Montgomery, 1986). This lends support to the belief that the differences in communication between the genders are different in styles and purpose, but not in outcome (MacGeorge et al., 2004; Tannen, 1990). This study also displayed that observed behavior becomes a very accurate predictor of attraction, perhaps even more than those predispositions of the participants towards those they were asked to rate for their perceived attraction (Montgomery, 1986).

Although the results of Montgomery (1986) support the belief that open communication does have more superiority in communication patterns, this study had several limitations that may cause this conclusion to not be as viable as face value would prescribe. During the interactions between the individuals in the research discussions, open communication may have been seen as socially appropriate behavior and, as a result, other behavior may have been unknowingly suppressed. Also bias, in the form of subjectivity of interaction with those whom the participants rated higher for social attractiveness, may interfere with any determinate results. The continual actions and reactions in response to one another in the discussions are likely to influence 
interpersonal attraction and may have confounding possibilities (Montgomery, 1986). However, on a general basis, those who engage in more open communication have more attraction reciprocated to them by the other participant. Perhaps most importantly, the substantial influence that speech style maintained in attraction demonstrated that regardless of the content of the speech, the listeners' focus is on the stereotypical communication pattern of the opposite gender.

\section{Conclusion}

Development of attraction between the genders is an intricate and dynamic process that cannot be accounted for by only one variable in interaction between individuals. Although much research has been devoted to studying attraction and the development of attraction in regards to many variables and conditions, the effects that specific communicative methods or styles of the genders have on attraction have not been thoroughly analyzed. Specifically, do stereotypical women communication patterns employed by men become more attractive to women than the typical men's approach to communication? How does the successful use of the other gender's communicative patterns impact perceived attraction? This study proposes a further defining of those interactive elements of general communication patterns of men and women and the effects these gender-specific communicative patterns have on attraction between the two genders. 
Method

\section{Participants.}

Participants $(\mathrm{N}=164)$ were solicited from four lower-level psychology classes on the Utah State University campus, were given optional credit for their psychology class and entered into a prize drawing for their participation. Ages of participants ranged from 18 to 51 with a mean of 21.43 years. Male participates numbered 73 , female participants 91 and all participants reported to be heterosexual. The majority of participants $(n=154)$ were of White/EuroAmerican descent and 78\% indicated they were of the LDS religion. Of the participants, $24 \%$ were declared psychology majors, $67 \%$ had never taken a psychology course previous to their current class, and 53\% were college freshman students. Only $35 \%$ indicated their involvement in a committed relationship, either dating or married.

\section{Materials.}

A survey questionnaire titled Attractive Communication Styles Survey was used in data collection. This survey is patterned closely after the Communication Styles Survey that was developed by Michaud and Warner (1997), which used similar questions to ascertain certain styles of communication. Likert-type questions were used in assessing the likelihood of participants responding in certain situations on a scale of 1-5, 1 being never responding that way and 5 being always responding that way. After reading the situation, the participant was asked whether they would respond in a man or woman stereotypical manner based on Edwards and Hamilton (2004) and Tannen (1990) by giving them six choices: change the subject and move on, tell a joke and provide humor, give advice, offer empathy and support, share a similar experience and ask further 
questions about feelings. Participants were asked to give a rating on the 1-5 scale for each of the six choices. Following the first five questions, another five questions gave similar scenarios and asked participants to indicate on the same scale how they would like those of the opposite gender to respond.

Tannen (1990) furthered the notion that men are more likely to use communication as a tool in the societal hierarchy involving problem solving and competition; women, on the other hand, value communication as a means of social networking for support, placing emphasis on intimacy and expression. Based upon this research, two brief conversations tailored to college-age individuals concerning normal life issues and decision making between two people of opposite gender were then distributed to the participants to read on paper. This included one conversation with a stereotypical man's communicative pattern and another conversation exhibiting typical woman's communicative patterns. In order to hold relative physical attractiveness constant, identical pictures were provided for both conversations. After the conversations were completely read, the Conversation Survey Questionnaire (CSQ) was administered to participants for assessment of attraction to the conversations. Several questions were asked to assess participant attraction to the conversation (e.g., who would you like to go on a date with, who are you most attracted to romantically?).

\section{Procedure}

In collaboration with Utah State University, the surveys were administered and completed on campus. The ACSS, conversations, and CSQ were all placed in packets and administered to participants following their verbal consent. Controlling for possible order effects, the ACSS and the CSQ were evenly distributed in order of appearance in 
the packet. Also, each conversation was evenly varied in order of appearance in the packets to control for any further possible order effects. Participants were informed that the study was about attraction and communication, but not informed of the hypotheses. Upon completion of the materials in the packet, participants were asked to sign an attendance sheet and a sheet for the prize drawing. All survey materials were kept in a locked cabinet following participation in the study. 


\section{Results}

$A C S S$

After conducting a series of independent samples t-tests, a few significant differences were revealed. Significant differences surfaced with men responding they were more likely to "tell a joke and provide humor" than women $(4.923(162)=x, p<.01)$. All other differences in participant responses about themselves were nonsignificant (see Table 1). Further significant differences were found when comparing the data asking the participants to rate attractiveness of communicative styles in the opposite gender (see Table 2). Women displayed a significant difference, being more likely to want men to "ask further questions about how they feel" $(-2.623(162)=x, p=.01)$. Although mean scores were extremely low for both gender scores, men also exhibited a tendency to desire "changing the subject and moving on" in prospective partners more than women did $(2.295(162)=x, p=.023)$. No other responses about attractiveness of the opposite gender's conversation pattern were found to have significant differences between the genders.

Table 1: Independent Samples t-tests for ACSS Self Ratings

\begin{tabular}{|c|c|c|c|c|c|}
\hline & Gender & Mean(SD) & $\mathrm{t}$ & $\mathrm{df}$ & $\mathrm{P}$ \\
\hline Offer Empathy and Support (Self) & $\begin{array}{c}\mathrm{M} \\
\mathrm{F}\end{array}$ & $\begin{array}{l}18.60(4.323) \\
19.71(4.256)\end{array}$ & -1.651 & 162 & .101 \\
\hline $\begin{array}{l}\text { Change the Subject and Move On } \\
\text { (Self) }\end{array}$ & $\begin{array}{c}\mathrm{M} \\
\mathrm{F}\end{array}$ & $\begin{array}{l}11.37(4.602 \\
10.11(4.661)\end{array}$ & 1.730 & 162 & .086 \\
\hline Give Advice (Self) & $\begin{array}{c}\mathrm{M} \\
\mathrm{F}\end{array}$ & $\begin{array}{l}17.59(4.521) \\
18.11(4.140)\end{array}$ & -.768 & 162 & .443 \\
\hline Share Similar Experiences (Self) & $\begin{array}{c}\mathrm{M} \\
\mathrm{F}\end{array}$ & $\begin{array}{l}12.08(3.908) \\
11.96(3.786)\end{array}$ & .209 & 162 & .835 \\
\hline $\begin{array}{c}\text { Tell a Joke and Provide Humor } \\
\text { (Self) }\end{array}$ & $\begin{array}{l}\mathrm{M} \\
\mathrm{F}\end{array}$ & $\begin{array}{l}16.77(4.489) \\
13.49(4.012)\end{array}$ & 4.923 & 162 & $<.000$ \\
\hline $\begin{array}{c}\text { Ask More Questions About How } \\
\text { They Feel (Self) }\end{array}$ & $\begin{array}{c}\mathrm{M} \\
\mathrm{F}\end{array}$ & $\begin{array}{l}18.75(4.139) \\
19.98(4.712)\end{array}$ & -1.745 & 162 & .083 \\
\hline
\end{tabular}


Table 2: Independent Samples t-tests for ACSS Ratings of Others

\begin{tabular}{|c|c|c|c|c|c|}
\hline & Gender & $\operatorname{Mean}(\mathrm{SD})$ & $\mathrm{t}$ & $\mathrm{df}$ & $\mathrm{P}$ \\
\hline $\begin{array}{l}\text { Offer Empathy and Support } \\
\text { (Others) }\end{array}$ & $\begin{array}{c}\mathrm{M} \\
\mathrm{F}\end{array}$ & $\begin{array}{l}18.78(5.386) \\
19.87(5.097)\end{array}$ & -1.324 & 162 & .187 \\
\hline $\begin{array}{l}\text { Change the Subject and Move On } \\
\text { (Others) }\end{array}$ & $\begin{array}{l}\mathrm{M} \\
\mathrm{F}\end{array}$ & $\begin{array}{r}10.63(5.130) \\
8.77(5.183) \\
\end{array}$ & 2.295 & 162 & .023 \\
\hline Give Advice (Others) & $\begin{array}{l}\mathrm{M} \\
\mathrm{F}\end{array}$ & $\begin{array}{l}17.99(4.683) \\
19.05(4.545)\end{array}$ & -1.476 & 162 & .142 \\
\hline $\begin{array}{l}\text { Share Similar Experiences } \\
\text { (Others) }\end{array}$ & $\begin{array}{l}\mathrm{M} \\
\mathrm{F}\end{array}$ & $\begin{array}{l}18.36(4.442) \\
18.68(3.374) \\
\end{array}$ & -.470 & 162 & .639 \\
\hline $\begin{array}{l}\text { Tell a Joke and Provide Humor } \\
\text { (Others) }\end{array}$ & $\begin{array}{l}\mathrm{M} \\
\mathrm{F}\end{array}$ & $\begin{array}{l}18.51(4.814) \\
17.48(4.503)\end{array}$ & 1.403 & 162 & .163 \\
\hline $\begin{array}{c}\text { Ask More Questions About How } \\
\text { They Feel (Others) }\end{array}$ & $\begin{array}{l}\mathrm{M} \\
\mathrm{F}\end{array}$ & $\begin{array}{l}17.40(5.150) \\
19.47(4.943)\end{array}$ & -2.623 & 162 & .010 \\
\hline
\end{tabular}

CSQ

Data collected from the CSQ suggest that participants showed a general inclination and preference toward the female type of communication. Females showed an intensely strong preference for the women type of communication with over $75 \%$ of the participants choosing a " 3 " or " 4 " for the majority of the questions. Although women tended to have an intense desire for their own gender's style of communication in their prospective partners, men did not prefer men's style, but their mean scores were all significantly on the women side of the scale. A single sample t-test revealed that both mean scores for the genders for all questions on the CSQ were significantly on the women side of the conversation scale $(6.350(72)=x, p<.01$; $13.811(90)=x, p<.01)($ see Table 3$)$. Over $70 \%$ of male participants chose a "3" or a "4" on many of the questions in the CSQ.

Further statistical analysis with a series of independent samples t-tests revealed significant differences between every single question on the CSQ between men and women 
except for "most attracted to romantically" (see Table 4). This exception, however, was

negligibly not significant with a $p$ value of .064 . Although all responses for both genders were

distributed on the women side of the communication scale, almost all questions displayed a significant difference between the genders.

Table 3: One Sample t-tests for Composite CSQ Scores Test Value $=2$

\begin{tabular}{|l|c|c|c|c|c|}
\hline & $\mathrm{N}$ & Mean(SD) & $\mathrm{T}$ & $\mathrm{df}$ & $\mathrm{p}$ \\
\hline Composite Scores (M) & 73 & $2.745(1.003)$ & 6.350 & 72 & $<.000$ \\
\hline Composite Scores (W) & 91 & $3.292(0.893)$ & 13.811 & 90 & $<.000$ \\
\hline
\end{tabular}

Table 4: Independent Samples t-tests Statistics for CSQ Questions

\begin{tabular}{|c|c|c|c|c|c|}
\hline & Gender & Mean(SD) & $\mathrm{t}$ & $\mathrm{df}$ & $\mathrm{p}$ \\
\hline Go on a Date With & $\begin{array}{c}\mathrm{M} \\
\mathrm{F}\end{array}$ & $\begin{array}{l}3.00(1.394) \\
3.37(1.029)\end{array}$ & -1.973 & 162 & .050 \\
\hline Talk to Again & $\begin{array}{c}\mathrm{M} \\
\mathrm{F}\end{array}$ & $\begin{array}{l}3.01(1.270) \\
3.54(1.088) \\
\end{array}$ & -2.827 & 160 & .005 \\
\hline See Again in the Future & $\begin{array}{l}\mathrm{M} \\
\mathrm{F}\end{array}$ & $\begin{array}{l}2.97(1.265) \\
3.54(1.047)\end{array}$ & -3.119 & 160 & .002 \\
\hline $\begin{array}{l}\text { Most Successful Romantic } \\
\text { Relationship }\end{array}$ & $\begin{array}{c}\mathrm{M} \\
\mathrm{F}\end{array}$ & $\begin{array}{c}3.00(1.242) \\
3.43(.921) \\
\end{array}$ & -2.522 & 160 & .013 \\
\hline Most Attracted to Romantically & $\begin{array}{c}\mathrm{M} \\
\mathrm{F}\end{array}$ & $\begin{array}{l}2.82(1.273) \\
3.18(1.151)\end{array}$ & -1.867 & 162 & .064 \\
\hline Be Friends With & $\begin{array}{l}\mathrm{M} \\
\mathrm{F}\end{array}$ & $\begin{array}{l}2.53(1.324) \\
3.09(1.355)\end{array}$ & -2.627 & 162 & .009 \\
\hline Have a Relationship With & $\begin{array}{c}\mathrm{M} \\
\mathrm{F}\end{array}$ & $\begin{array}{l}3.01(1.173) \\
3.40(1.031)\end{array}$ & -2.217 & 162 & .028 \\
\hline Give Phone \# or Contact Info to & $\begin{array}{l}\mathrm{M} \\
\mathrm{F}\end{array}$ & $\begin{array}{c}2.88(1.233) \\
3.34(.914) \\
\end{array}$ & -2.782 & 160 & .006 \\
\hline $\begin{array}{c}\text { Try to Flirt with Next Time You } \\
\text { Meet }\end{array}$ & $\begin{array}{l}\mathrm{M} \\
\mathrm{F}\end{array}$ & $\begin{array}{l}2.33(1.450) \\
3.03(1.308)\end{array}$ & -3.140 & 152 & .002 \\
\hline Tell Your Friends About & $\begin{array}{c}\mathrm{M} \\
\mathrm{F} \\
\end{array}$ & $\begin{array}{l}2.42(1.479) \\
3.14(1.224) \\
\end{array}$ & -3.266 & 152 & .001 \\
\hline
\end{tabular}




\section{Discussion}

The data collected on the ACSS were supportive of some of the expectations of this study and contradictory of others. Men were more likely to "tell a joke and provide humor," supporting the notion of Tannen (1990) that men are "generators of humor." Women did not rate a stronger preference for "tell a joke and provide humor" in their ratings of prospective partners, however, offering no support to her theory that women are "appreciators of humor." Given the literature on genders and gender communication we expected men further to define themselves according to other types of male-typical communicative patterns (i.e., give advice, change the subject), but this was not the case. Men were less likely to define themselves with these communicative patterns than women. This may be explained broadly by the negative connotation that may be attached to these two communicative patterns. Both men and women may not want to be known as selfish by giving their own advice or by changing the subject when they are uncomfortable regardless of what they may do in reality.

Women did display a significant preference more than men for men to "ask further questions about how they feel," supporting the earlier research findings of women preferring their own gender style of communication. We further expected to see more differences in women responses, defining themselves according to the women style of communication than was evident in the results. The free response setup of the ACSS may have contributed to this discrepancy since participants could rate themselves on each of the six communicative patterns, making it possible for all participants to score themselves highly on those qualities they viewed positively.

The original hypotheses were all supported by the collected data on the CSQ. Women expressed a tendency to prefer their own gender's type of communication pattern in attraction to 
the opposite gender. Women exhibited a strong preference for men who had verbal communication skills including expressing empathy and concern, sharing similar experiences, and asking further questions about how they feel. This further supports Tannen's (1990) hypothesis of women desiring men to understand them and communicate with them on a more open manner. The strong emphasis that women placed on the opposite gender's ability to "ask further questions about how they feel" on the ACSS also support the findings of Montgomery (1986) suggesting open communication styles, usually associated with women patterns of communication, are more desirable to women. The slight preference that men exhibited for women patterns in the CSQ questions also supports Montgomery's (1986) finding that open communication preferences did not vary across the gender variable.

Although men and women responses did favor the women types of communication on the CSQ, there were still significant differences between the genders on several of the questions. This finding may be the result of differing intensities of attraction the genders have toward the stereotypical communicative patterns of women. Mean scores suggest that women strongly favor the communication patterns associated with their gender and men slightly favor those same verbal patterns. This finding suggests that gender difference in attraction may not be as evident in verbal communicative patterns as has been suggested by earlier research, but only differs in the intensity of attraction.

The typical difficulties associated with self-report measures are the principle limitations of this study. The social pressure to "look good" or to conform to local social standards and expectations, regardless of secured anonymity, may have caused participants to bias their responses. In a possible attempt to avoid cognitive dissonance, participants may have responded according to how they hope or believe they will become rather than an objective interpretation of 
themselves. Furthermore, verbal and written descriptions of how a participant would act or want others to act may be very different from the way the participant does act or want others to act in a similar situation in reality. A research design that circumvents these difficulties (i.e., behavioral observation, dyadic interactions) would be ideal for further research on the influence of gender communicative patterns on attraction formation between the genders. Additionally, a statistically proven measurement for the conversations should be developed and employed with any further study on conversations and their influence on opposite gender attraction. 


\section{References}

Braun, C., Gruendl, M. et al. (2001). Beautycheck - Ursachen und Folgen von

Attraktivitaet. Report. [pdf-document]. Available from:

http://www.beautycheck.de/english/bericht/bericht.htm

Burgoon, J. K., Coker, D. A., \& Coker, R. A. (1986). Communicative effects of gaze

behavior: a test of two contrasting explanations. Human Communication Research, 12(4), 495-524.

Buss, D. (1989). Sex differences in human mate preferences: evolutionary hypotheses tested in 37 cultures. Behavioral and Brain Sciences, 12, 1-49.

Cramer, R. E. \& Schaeffer, J. T. (1996). Identifying the ideal mate: more evidence for male-female convergence. Current Psychology, 15(2), 157-167.

Edwards, R. \& Hamilton, M. A. (2004). You need to understand my gender role: an empirical test of Tannen's model of gender and communication. Sex Roles, 50(7/8), 491504.

Feldstein, S., Dohm, F. \& Crown, C. L. (2001). Gender and speech rate in the perception of competence and social attractiveness. The Journal of Social Psychology, 141(6), 785 806.

Kalof, L. (1999). Stereotyped evaluative judgments and female attractiveness. Gender Issues, 17(2), 68-83).

MacGeorge, E. L., Graves, A. R., Feng, B., Gillihan, S. J. \& Burleson, B. R. (2004). The myth of gender cultures: similarities outweigh differences in men's and women's provision of and responses to supportive communication. Sex Roles, 50(3/4), 143-147. 
Michaud, S. L. \& Warner, R. M. (1997). Gender Differences in Self-Reported Response to Troubles Talk. Sex Roles, 37(7/8), 527-540.

Montgomery, B. (1986). Interpersonal attraction as a function of open communication and gender. Communication Research Reports, 3, 140-145.

Raines, R. S., Hechtman, S. B. \& Rosenthal, R. (1990). Nonverbal behavior and gender as determinants of physical attractiveness. Journal of Nonverbal Behavior, 14(4), 253-267.

Regan, P. C. \& Joshi, A. (2003). Ideal partner preferences among adolescents. Social Behavior and Personality, 31(1), 13-20.

Rowatt, W. C., Cunningham, M. R. \& Druen, P. B. (1999). Lying to get a date: the effect of facial physical attractiveness on the willingness to deceive prospecte dating partners. Journal of Social and Personal Relationships, 16(2), 209-223.

Sprecher, S. \& Regan, P. C. (2002). Liking some things (in some people) more than others: partner preferences in romantic relationships and friendships. Journal of Social and Personal Relationships, 19(4), 463-481.

Tannen, D. (1990). You just don't understand: women and men in conversation. New York: William Morrow and Company, Inc.

Wagner, H. L., Buck, R. \& Winterbotham, M. (1993). Communication of specific emotions: gender differences in sending accuracy and communication measures. Journal of Nonverbal Behavior, 17(1), 29-53. 


\section{ATTRACTIVE COMMUNICATION STYLES SURVEY}

\section{Instructions: All information is confidential and anonymous. Please respond honestly.}

1. Age:

2. Gender: $\square$ Masculine $\square$ Feminine $\square$ Other

3. Sexual Preference: $\square$ Heterosexual $\square$ Homosexual $\square$ Other

4. Race: $\square$ African American/Black

$\square$ Asian American

$\square$ Hispanic/Latina(o)/Mexican American

$\square$ White/European American $\square$ Middle Eastern/Arabic American

$\square$ Native American/American Indian

$\square$ Multiracial (specify)

$\square$ Other (specify)

5. Religion (ex: LDS, Catholic, Baptist, Buddhist):

6. Home town/state (ex: Pleasant Grove, UT)

7. What is your anticipated or declared undergraduate major?

8. How many psychology courses have you taken while attending college? $\square 1 \quad \square 2 \quad \square 3 \quad \square 3<$

9. How many semesters have you taken while attending college? $\square 1 \quad \square 2 \quad \square 3 \quad \square 3<$

10. Are you married? $\square$ Yes $\square$ No

11. Are you currently in a committed relationship with a boy/girlfriend? $\square$ Yes $\square$ No

Instructions: The following questions are in a Likert-type scaled form. A I means that you always would respond that way and a 5 means that you never would respond that way. Choose the number that best corresponds to how you would respond in the given situation. Please mark a number for each alternative option. Questions 1-10.

1. Suppose someone from the opposite gender were to tell you that he/she is considering breaking up with his/her boy/girlfriend. How would you respond?

\begin{tabular}{|l|l|l|l|l|l|}
\hline Offer empathy and support & 1 & 2 & 3 & 4 & 5 \\
\hline Change the subject and move on & 1 & 2 & 3 & 4 & 5 \\
\hline Give advice and help him/her solve the problem & 1 & 2 & 3 & 4 & 5 \\
\hline Share a similar experience you have had yourself & 1 & 2 & 3 & 4 & 5 \\
\hline Tell a joke and provide humor & 1 & 2 & 3 & 4 & 5 \\
\hline Ask further questions about how they feel & 1 & 2 & 3 & 4 & 5 \\
\hline
\end{tabular}


2. Someone of the opposite gender describes his/her future dream career to you after he/she has completed his/her undergraduate study. How would you respond?

\begin{tabular}{|l|l|l|l|l|l|}
\hline Offer empathy and support & 1 & 2 & 3 & 4 & 5 \\
\hline Change the subject and move on & 1 & 2 & 3 & 4 & 5 \\
\hline Give advice and help him/her solve the problem & 1 & 2 & 3 & 4 & 5 \\
\hline Share a similar experience you have had yourself & 1 & 2 & 3 & 4 & 5 \\
\hline Tell a joke and provide humor & 1 & 2 & 3 & 4 & 5 \\
\hline Ask further questions about how they feel & 1 & 2 & 3 & 4 & 5 \\
\hline
\end{tabular}

3. Imagine that someone of the opposite gender you know were to relate a very sensitive family issue (e.g. death, arrest) with you after class. How would you respond?

Offer empathy and support

Change the subject and move on

Give advice and help him/her solve the problem

Share a similar experience you have had yourself

Tell a joke and provide humor

Ask further questions about how they feel

\begin{tabular}{|l|l|l|l|l|}
\hline 1 & 2 & 3 & 4 & 5 \\
\hline 1 & 2 & 3 & 4 & 5 \\
\hline 1 & 2 & 3 & 4 & 5 \\
\hline 1 & 2 & 3 & 4 & 5 \\
\hline 1 & 2 & 3 & 4 & 5 \\
\hline 1 & 2 & 3 & 4 & 5 \\
\hline
\end{tabular}

4. While working with someone of the opposite gender that you know, he/she relates how much he/she is dissatisfied and upset with the job that he/she is involved in. How would you respond?

Offer empathy and support

Change the subject and move on

Give advice and help him/her solve the problem

Share a similar experience you have had yourself

Tell a joke and provide humor

Ask further questions about how they feel

\begin{tabular}{|l|l|l|l|l|}
\hline 1 & 2 & 3 & 4 & 5 \\
\hline 1 & 2 & 3 & 4 & 5 \\
\hline 1 & 2 & 3 & 4 & 5 \\
\hline 1 & 2 & 3 & 4 & 5 \\
\hline 1 & 2 & 3 & 4 & 5 \\
\hline 1 & 2 & 3 & 4 & 5 \\
\hline
\end{tabular}

5. Suppose that as you are going to church, someone you know from the opposite gender tells you how much he/she does not enjoy going to church. How would you respond?

\begin{tabular}{|l|l|l|l|l|l|}
\hline Offer empathy and support & 1 & 2 & 3 & 4 & 5 \\
\hline Change the subject and move on & 1 & 2 & 3 & 4 & 5 \\
\hline Give advice and help him/her solve the problem & 1 & 2 & 3 & 4 & 5 \\
\hline Share a similar experience you have had yourself & 1 & 2 & 3 & 4 & 5 \\
\hline Tell a joke and provide humor & 1 & 2 & 3 & 4 & 5 \\
\hline Ask further questions about how they feel & 1 & 2 & 3 & 4 & 5 \\
\hline
\end{tabular}

6. Suppose that you have just finished your classes for the week and you are trying to decide out of the many options you have on what to do for the weekend. Someone you know from the opposite gender comes up to you and talks with you. How would you like him/her to respond to your concern?

\begin{tabular}{|l|l|l|l|l|l|}
\hline Offer empathy and support & 1 & 2 & 3 & 4 & 5 \\
\hline Change the subject and move on & 1 & 2 & 3 & 4 & 5 \\
\hline Give advice and help him/her solve the problem & 1 & 2 & 3 & 4 & 5 \\
\hline Share a similar experience you have had yourself & 1 & 2 & 3 & 4 & 5 \\
\hline Tell a joke and provide humor & 1 & 2 & 3 & 4 & 5 \\
\hline
\end{tabular}


7. Imagine that you are faced with a large decision on what to do with a relationship that you see going nowhere in the future and you are discussing it with a person you know of the opposite gender. How would you like him/her to respond to your situation?

\begin{tabular}{|l|l|l|l|l|l|}
\hline Offer empathy and support & 1 & 2 & 3 & 4 & 5 \\
\hline Change the subject and move on & 1 & 2 & 3 & 4 & 5 \\
\hline Give advice and help him/her solve the problem & 1 & 2 & 3 & 4 & 5 \\
\hline Share a similar experience you have had yourself & 1 & 2 & 3 & 4 & 5 \\
\hline Tell a joke and provide humor & 1 & 2 & 3 & 4 & 5 \\
\hline Ask further questions about how they feel & 1 & 2 & 3 & 4 & 5 \\
\hline
\end{tabular}

8. You have been given the responsibility to help in a church function in your religious affiliation. Someone you know from the opposite gender is talking with you. How would you like him/her to respond?

\begin{tabular}{|l|l|l|l|l|l|}
\hline Offer empathy and support & 1 & 2 & 3 & 4 & 5 \\
\hline Change the subject and move on & 1 & 2 & 3 & 4 & 5 \\
\hline Give advice and help him/her solve the problem & 1 & 2 & 3 & 4 & 5 \\
\hline Share a similar experience you have had yourself & 1 & 2 & 3 & 4 & 5 \\
\hline Tell a joke and provide humor & 1 & 2 & 3 & 4 & 5 \\
\hline Ask further questions about how they feel & 1 & 2 & 3 & 4 & 5 \\
\hline
\end{tabular}

9. As you relate an experience you had while with your family with someone of the opposite gender, how would you like him/her to respond?

\begin{tabular}{|l|l|l|l|l|l|}
\hline Offer empathy and support & 1 & 2 & 3 & 4 & 5 \\
\hline Change the subject and move on & 1 & 2 & 3 & 4 & 5 \\
\hline Give advice and help him/her solve the problem & 1 & 2 & 3 & 4 & 5 \\
\hline Share a similar experience you have had yourself & 1 & 2 & 3 & 4 & 5 \\
\hline Tell a joke and provide humor & 1 & 2 & 3 & 4 & 5 \\
\hline Ask further questions about how they feel & 1 & 2 & 3 & 4 & 5 \\
\hline
\end{tabular}

10. Suppose you relate a negative experience you had with your boss at your job one night to a person of the opposite gender that you know. How would like him/her to respond?

\begin{tabular}{|l|l|l|l|l|l|}
\hline Offer empathy and support & 1 & 2 & 3 & 4 & 5 \\
\hline Change the subject and move on & 1 & 2 & 3 & 4 & 5 \\
\hline Give advice and help him/her solve the problem & 1 & 2 & 3 & 4 & 5 \\
\hline Share a similar experience you have had yourself & 1 & 2 & 3 & 4 & 5 \\
\hline Tell a joke and provide humor & 1 & 2 & 3 & 4 & 5 \\
\hline Ask further questions about how they feel & 1 & 2 & 3 & 4 & 5 \\
\hline
\end{tabular}


Instructions: Rate the importance of the following verbal communicative qualities in the opposite gender. The closer the number is to the quality, the more important that quality is to you in someone of the opposite gender. Questions 11-18.

11

Sympathy

\begin{tabular}{|l|l|l|l|l|l|c|}
\hline 1 & 2 & 3 & 4 & 5 & 6 & 7 \\
\hline
\end{tabular}

12

Give Advice

Share Similar Experiences

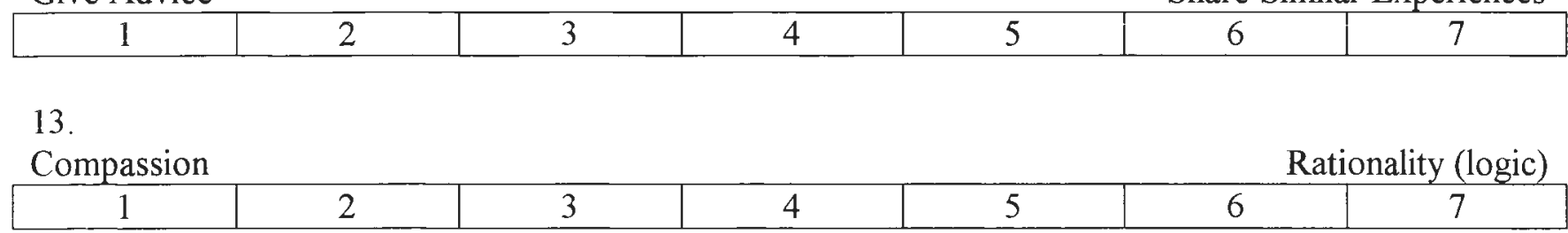

14.

Problem Solving

\begin{tabular}{|c|c|c|c|c|c|c|}
\hline 1 & 2 & 3 & 4 & 5 & 6 & 7 \\
\hline
\end{tabular}

15

Objectivity(unbiased/logical)

Subjectivity(personal)

16.

Intimacy

\begin{tabular}{|l|l|l|l|l|l|}
\hline 2 & 3 & 4 & 5 & 6 & 7 \\
\hline
\end{tabular}

Intimacy
\begin{tabular}{|l|l|l|l|l|l|c|}
\hline 1 & 2 & 3 & 4 & 5 & 6 & 7 \\
\hline 17. \\
Compromise \\
\hline 1 & 2 & 3 & 4 & 5 & 6 & Competition \\
\hline
\end{tabular}

18.

Express Affection

Instructions: Fill in the blank. Questions 19-20.

19. The most attractive quality in verbal interaction with the opposite sex is

20. The most unattractive or least desirable quality in verbal interaction with the opposite sex is 


\section{GENDER CONVERSATION \#1}

Instructions: Read through this conversation as if you were the person designated as "Woman" or "W" talking with Single Guy \#1.

Woman: How was your day?

Single Guy $\# 1 \rightarrow$

Single Guy \#1: Fine.

W: What did you do? Weren't you doing something with that

club activity you told me about?

Single Guy \#1: No, that is actually tomorrow, I just went to

class today. I still have to get things ready for tomorrow's club

activity. I am responsible for contacting the professors and making sure they know what they will be speaking on. I also need to find a classroom where we can hold the activity, anyway.

W: Great! My day was great. I had pizza in my first class because we all turned in our homework on time. We also were able to get a free meal at the Hub if we signed up for a credit card. It was a good meal. In fact, I think any free meal is good, don't you?

Single Guy \#1: Sure.

W: I did run into a problem today, though. I found out that I have an extraneous credit charge to my card that I never made myself. I think someone might have taken my card number or something. It's for like $\$ 500$ and I'm not going to pay it because I didn't charge it.

Single Guy \#1: Why don't you just contact the credit card company and explain your predicament? 
W: Well, I already tried that, but they just won't listen. I tell them it wasn't me, but they say since it was my card, I am ultimately responsible for the payment of the $\$ 500$. I just don't know what to do.

Single Guy \#1: Honestly, it just sounds like to me that you should call them up, use a little assertiveness, and let them know you are not going to pay it.

W: I have a rough time with being assertive, though. There was this one relationship that I was in and I knew it wasn't going anywhere. But, I just couldn't bring myself to talk to him about breaking up. I knew it would break his heart and I felt so bad. That's just how I am. I don't like uncomfortable situations involving confrontation.

Single Guy \#1: Well, you'll just have to stand up for yourself to this credit card corporation in some way or you will have to pay the money. Speaking of relationships, I heard this good pick up line the other day. [he asks her directly] So, do you have a garden?

W: What? I guess - back home I do. Why?

Single Guy \#1: Because I want to plant my "two" lips next to yours! [he laughs] 


\section{GENDER CONVERSATION \#2}

Instructions: Read through this conversation as if you were the person designated as "Woman" or "W" talking with Single Guy \#2.

Woman: How was your day?

Single Guy $\# 2 \rightarrow$

Single Guy \#2: Great. I had a wonderful day with my friends.

How about you? Did you have a good day?

W: Yes. Thank you for asking. Weren't you doing something

today with that club activity you told me about?

Single Guy \#2: No, that is actually tomorrow, I just went to

class today with my friends. I still have to get things ready for tomorrow's club activity.

They want me to contact the professors and make sure they know what they will be speaking on. I will also be asking around to find a classroom where we can hold the activity - maybe I'll ask the secretary up on the $4^{\text {th }}$ floor, she's pretty smart and has helped me before. Why was your day great?

W: Boy, was it great! My day was really great. I had pizza in my first class because we all turned in our homework on time. We also were able to get a free meal at the Hub if we signed up for a credit card. It was a good meal. In fact, I think any free meal is good, don't you?

Single Guy \#2: Definitely. I usually try to do those things with my friends, though. I have a rough time giving out my information to strange people. Who knows what they'll do with my information?

W: Amazing! I did run into a similar problem today! I found out that I have an extraneous credit charge to my card that I never made myself. I think someone might 
have taken my card number or something. It's for like $\$ 500$ and I'm not going to pay it because I didn't charge it.

Single Guy \#2: Oh, I'm so sorry to hear that! That's precisely why I have a rough time trusting people with that information about myself. What have you decided you will do? W: Well, I decided to call up the credit card company and tell them that I didn't make the charges on my card, but they just won't listen. I tell them it wasn't me, but they say since it was my card, I am ultimately responsible for the payment of the $\$ 500$. I just don't know what to do.

Single Guy \#2: So, you already called them up and they said they can't do anything for you? Sounds like they don't understand. Is there anything I can do to help?

W: No, but thanks. I just have a rough time with being assertive, I guess. There was this one relationship that I was in and I knew it wasn't going anywhere. But, I just couldn't bring myself to talk to him about breaking up. I knew it would break his heart and I felt so bad. That's just how I am. I don't like uncomfortable situations involving confrontation.

Single Guy \#2: I hate those situations too. It always seems like those predicaments are the hardest to get out of. Maybe being assertive is the answer, but if there is anything I can do, you'll make sure to let me know, right?

W: Yeah, sure. Thank you so much!

\section{GENDER CONVERSATION \#3}

Instructions: Read through this conversation as if you were the person designated as 
"Man" or "M" talking with Single Girl \#3.

Man: How was your day?

Single Girl \#3 $\rightarrow$

Single Girl \#3: Fine.

M: What did you do? Weren't you doing something with that club activity you told me about?

Single Girl \#3: No, that is actually tomorrow, I just went to class today. I still have to get things ready for tomorrow's club activity. I am responsible for contacting the professors and making sure they know what they will be speaking on. I also need to find a classroom where we can hold the activity, anyway.

M: Good! My day was great. I had pizza in my first class because we all turned in our homework on time. We also were able to get a free meal at the Hub if we signed up for a credit card. It was a good meal. In fact, I think any free meal is good, don't you?

Single Girl \#3: Sure.

M: I did run into a problem today, though. I found out that I have an extraneous credit charge to my card that I never made myself. I think someone might have taken my card number or something. It's for like $\$ 500$ and I'm not going to pay it because I didn't charge it.

Single Girl \#3: Why don't you just contact the credit card company and explain your predicament?

M: Well, I already tried that, but they just won't listen. I tell them it wasn't me, but they say since it was my card, I am ultimately responsible for the payment of the $\$ 500$. I just don't know what to do. 
Single Girl \#3: Honestly, it just sounds like to me that you should call them up, use a little assertiveness, and let them know you are not going to pay it.

M: I have a rough time with being assertive, though. There was this one relationship that I was in and I knew it wasn't going anywhere. But, I just couldn't bring myself to talk to her about breaking up. I knew it would break her heart and I felt so bad. That's just how I am. I don't like uncomfortable situations involving confrontation.

Single Girl \#3: Well, you'll just have to stand up for yourself to this credit card corporation in some way or you will have to pay the money. Speaking of relationships, I heard this good pick up line the other day. [she asks him directly] So, do you have a garden?

M: What? I guess - back home I do. Why?

Single Girl \#3: Because I want to plant my "two" lips next to yours! [she laughs]

\section{GENDER CONVERSATION \#4}

Instructions: Read through this conversation as if you were the person designated as "Man" or "M" talking with Single Girl \#4. 
Man: How was your day?

Single Girl \#4 $\rightarrow$

Single Girl \#4: Great. I had a wonderful day with my friends.

How about you? Did you have a good day?

M: Yes. Thank you for asking. Weren't you doing something

today with that club activity you told me about?

Single Girl \#4: No, that is actually tomorrow, I just went to

class today with my friends. I still have to get things ready for tomorrow's club activity.

They want me to contact the professors and make sure they know what they will be

speaking on. I will also be asking around to find a classroom where we can hold the

activity - maybe I'll ask the secretary up on the $4^{\text {th }}$ floor, she's pretty smart and has

helped me before. Why was your day great?

M: Boy, was it great! My day was really great. I had pizza in my first class because we all turned in our homework on time. We also were able to get a free meal at the Hub if we signed up for a credit card. It was a good meal. In fact, I think any free meal is good, don't you?

Single Girl \#4: Definitely. I usually try to do those things with my friends, though. I have a rough time giving out my information to strange people. Who knows what they'll do with my information?

M: Amazing! I did run into a similar problem today! I found out that I have an extraneous credit charge to my card that I never made myself. I think someone might have taken my card number or something. It's for like $\$ 500$ and I'm not going to pay it because I didn't charge it.

Single Girl \#4: Oh, I'm so sorry to hear that! That's precisely why I have a rough time trusting people with that information about myself. What have you decided you will do? 
M: Well, I decided to call up the credit card company and tell them that I didn't make the charges on my card, but they just won't listen. I tell them it wasn't me, but they say since it was my card, I am ultimately responsible for the payment of the $\$ 500$. I just don't know what to do.

Single Girl \#4: So, you already called them up and they said they can't do anything for you? Sounds like they don't understand. Is there anything I can do to help?

M: No, but thanks. I just have a rough time with being assertive, I guess. There was this one relationship that I was in and I knew it wasn't going anywhere. But, I just couldn't bring myself to talk to her about breaking up. I knew it would break her heart and I felt so bad. That's just how I am. I don't like uncomfortable situations involving confrontation.

Single Girl \#4: I hate those situations too. It always seems like those predicaments are the hardest to get out of. Maybe being assertive is the answer, but if there is anything I can do, you'll make sure to let me know, right?

M: Yeah, sure. Thank you so much! 


\section{CONVERSATION SURVEY QUESTIONNAIRE}

Instructions: After reading conversations \# $1 \&$ \&2, rate the single guys in the conversations according to your own opinion. Pick the answer that best coincides with your thoughts and feelings.

1. After having both of these conversations, which would you rather

Go on a date with?

\begin{tabular}{|l|l|l|l|l|}
\hline Single Guy \#1 & Moderately \#1 & Undecided & Moderately \#2 & Single Guy \#2 \\
\hline
\end{tabular}

Talk to again?

\begin{tabular}{|l|l|l|l|l|}
\hline Single Guy \#1 & Moderately \#1 & Undecided & Moderately \#2 & Single Guy \#2 \\
\hline
\end{tabular}

See again in the future?

\begin{tabular}{|l|l|l|l|l|}
\hline Single Guy \#1 & Moderately \#1 & Undecided & Moderately \#2 & Single Guy \#2 \\
\hline
\end{tabular}

2. After both of these conversations, which would you feel you might

Have the most successful romantic relationship with?

\begin{tabular}{|l|l|l|l|l|}
\hline Single Guy \#1 & Moderately \#1 & Undecided & Moderately \#2 & Single Guy \#2 \\
\hline
\end{tabular}

Be most attracted to romantically?

\begin{tabular}{|l|c|c|c|c|}
\hline Single Guy \#1 & Moderately \#1 & Undecided & Moderately \#2 & Single Guy \#2 \\
\hline
\end{tabular}

Not be interested in at all?

\begin{tabular}{|l|c|c|c|c|}
\hline Single Guy \#1 & Moderately \#1 & Undecided & Moderately \#2 & Single Guy \#2 \\
\hline
\end{tabular}

3. After finishing both conversations, who would you rather

Be friends with?

\begin{tabular}{|l|l|l|l|l|}
\hline Single Guy \#1 & Moderately \#1 & Undecided & Moderately \#2 & Single Guy \#2 \\
\hline
\end{tabular}

Have a relationship with?

\begin{tabular}{|l|l|l|l|l|}
\hline Single Guy \#1 & Moderately \#1 & Undecided & Moderately \#2 & Single Guy \#2 \\
\hline
\end{tabular}

Not pursue either a friendship or relationship with?

\begin{tabular}{|l|l|l|l|l|} 
Single Guy \#1 & Moderately \#1 & Undecided & Moderately \#2 & Single Guy \#2 \\
\hline
\end{tabular}

4. After having both conversations, who would you

Give your phone number or contact information to? 


\begin{tabular}{|l|l|l|l|l|}
\hline Single Guy \#1 & Moderately \#1 & Undecided & Moderately \#2 & Single Guy \#2 \\
\hline
\end{tabular}

Try to flirt with the next time you meet?

\begin{tabular}{|l|l|l|l|l|}
\hline Single Guy\#1 & Moderately \#1 & Undecided & Moderately \#2 & Single Guy \#2 \\
\hline
\end{tabular}

Tell your friends about?

\begin{tabular}{|l|l|l|l|l|}
\hline Single Guy \#1 & Moderately \#1 & Undecided & Moderately \#2 & Single Guy \#2 \\
\hline
\end{tabular}

5. Which conversation did you enjoy the most and why?

6. Which conversation did you enjoy the least and why? 


\section{CONVERSATION SURVEY QUESTIONNAIRE}

Instructions: After reading conversations $\# 3 \& \# 4$, rate the single girls in the conversations according to your own opinion. Pick the answer that best coincides with your thoughts and feelings.

1. After having both of these conversations, which would you rather

Go on a date with?

\begin{tabular}{|l|c|c|c|c|}
\hline Single Girl \#3 & Moderately \#3 & Undecided & Moderately \#4 & Single Girl \#4 \\
\hline
\end{tabular}

Talk to again?

\begin{tabular}{|l|l|l|l|l|}
\hline Single Girl \#3 & Moderately \#3 & Undecided & Moderately \#4 & Single Girl \#4 \\
\hline
\end{tabular}

See again in the future?

\begin{tabular}{|l|c|c|c|c|}
\hline Single Girl \#3 & Moderately \#3 & Undecided & Moderately \#4 & Single Girl \#4 \\
\hline
\end{tabular}

2. After both of these conversations, which would you feel you might

Have the most successful romantic relationship with?

\begin{tabular}{|l|c|c|c|c|}
\hline Single Girl \#3 & Moderately \#3 & Undecided & Moderately \#4 & Single Girl \#4 \\
\hline
\end{tabular}

Be most attracted to romantically?

\begin{tabular}{|c|c|c|c|c|}
\hline Single Girl \#3 & Moderately \#3 & Undecided & Moderately \#4 & Single Girl \#4 \\
\hline \multicolumn{5}{|c|}{ Not be interested in at all? } \\
\hline Single Girl \#3 & Moderately \#3 & Undecided & Moderately \#4 & Single Girl \#4 \\
\hline
\end{tabular}

3. After finishing both conversations, who would you rather

Be friends with?

\begin{tabular}{|l|l|l|l|l|}
\hline Single Girl \#3 & Moderately \#3 & Undecided & Moderately \#4 & Single Girl \#4 \\
\hline
\end{tabular}

Have a relationship with?

\begin{tabular}{|l|l|l|l|l|}
\hline Single Girl \#3 & Moderately \#3 & Undecided & Moderately \#4 & Single Girl \#4 \\
\hline
\end{tabular}

Not pursue either a friendship or relationship with?

\begin{tabular}{|l|c|c|c|c|}
\hline Single Girl \#3 & Moderately \#3 & Undecided & Moderately \#4 & Single Girl \#4 \\
\hline
\end{tabular}

4. After having both conversations, who would you

Give your phone number or contact information to?

\begin{tabular}{|l|l|l|l|l|}
\hline Single Girl \#3 & Moderately \#3 & Undecided & Moderately \#4 & Single Girl \#4 \\
\hline
\end{tabular}


Try to flirt with the next time you meet?

\begin{tabular}{|l|c|c|c|c|}
\hline Single Girl \#3 & Moderately \#3 & Undecided & Moderately \#4 & Single Girl \#4 \\
\hline
\end{tabular}

Tell your friends about?

\begin{tabular}{|l|c|c|c|c|}
\hline Single Girl \#3 & Moderately \#3 & Undecided & Moderately \#4 & Single Girl \#4 \\
\hline
\end{tabular}

5. Which conversation did you enjoy the most and why?

6. Which conversation did you enjoy the least and why? 